\title{
EFFECTIVENESS OF PHYSICAL THERAPY INTERVENTIONS FOR CHILDREN WITH CEREBRAL PALSY
}

\author{
M.D. Crăciunn'1), N.Midrigan²) \\ ${ }^{1,2)}$ University "Stefan cel Mare" Suceava Romania, \\ danielacr@usv.ro
}

\begin{abstract}
Cerebral palsy (CP) describes a group of permanent disorders of motor development and posture that cause limiting activity that are attributed to non-progressive dysfunctions occurring in the development of fetal brain or of the child.

The main purpose of the paper is to study the clinical and functional aspects with implications in the design and evaluation of the complex recovery therapy of the child with psycho-neuro-motor disabilities diagnosed with infantile cerebral palsy (ICP).

The study took place during the period June 2016 - March 2018, is of the type prospectively and comprised 5 children diagnosed with ICP, aged 4 to 12 years. Criteria for inclusion in the recovery group: children diagnosed with infantile cerebral palsy form spastic tetra-spastic, without orthopedic surgery, during the study period. Children have been given a comprehensive assessment of body attitude, upper and lower limb hypertonia, upper limbs functionality, and global motor function.

The major objective of recovering the child with infantile cerebral palsy was to improve the quality of life by creating conditions for minimum patient autonomy. The functional recovery program was carried out three times a week using exercises and methods of neuro-motor rehabilitation. Duration of the session was 50-60 min.

Due to the results obtained at the initial and final evaluation, a tonus improvement was observed in all the tested muscles, with a decrease in the mobilization resistance of all the muscle groups. In global functional evaluation the total score on the 5 sections of the 5 children with CP had an initial mean value of $34.92( \pm 16.60)$ and a final of $47.72( \pm 26.53)$

Stretching, neuro-motor reeducation methods and active physical exercises help to increase the degree of the functional independence.
\end{abstract}

Key words: cerebral palsy, physical therapy, hypertonia, functionality

\section{Introduction}

Cerebral palsy (PC) describes a group of permanent disorders of motor development and posture, which cause limiting activity, which are attributed to non progressive dysfunctions that occur in the development of fetal brain or during childhood. These motor disorders of cerebral palsy are often accompanied by sensory, perceptual, cognitive, communication, and behavioral disorders, epilepsy and secondary musculoskeletal disorders. [1,2]

The spastic form of cerebral palsy is considered to be the most common occurring in $70-80 \%$ of all cases. It is based on a lesion of the pyramidal system and is characterized by an increased muscle tone (hypertonic spasticity) distributed to certain muscular groups and present permanently, even during rest. These motor disorders of cerebral palsy are often accompanied by sensory, perceptual, cognitive, communication, and behavioral disorders, epilepsy and secondary muscular-chest disorders. [3, 4]

According to international statistics, the incidence of CP is 3 cases per 1,000 live births. In Romania it is approximated about 500 children affected annually, therefore it can be estimated, about 5,000 children suffering from physical disabilities caused by cerebral motor infirmity[5]. 
The main purpose of the paper is to study the clinical and functional aspects with implications in designing and evaluating a complex recovery therapy of the child with psycho-neuro-motor disabilities diagnosed with infantile cerebral palsy in accordance with validated worldwide terminology. The design and implementation of an intervention program based on diagnosis focuses on adapting the individual to the conditions of outstanding disability and ensuring functional independence.

\section{Material and method}

The study took place during the period June 2016 - March 2018 is typically observed level longitudinal, prospective and enrolled 5 children diagnosed with ICP (infantile cerebral palsy), spastic form, selected from a group of 8 children aged 4 to 12 years at the beginning of the research.

Criteria for inclusion in the Recovery lot: Children diagnosed with infantile cerebral palsy the spastic form, spastic tetra-paresis, without orthopedic surgery during study.

Table 1 Subjects included in the study

\begin{tabular}{|c|c|c|c|c|}
\hline NO.CRT. & $\begin{array}{c}\text { NAME } \\
\text { AND } \\
\text { SURNAME }\end{array}$ & DIAGNOSTIC & AGE & SEX \\
\hline 1. & $\mathrm{CM}$ & $\begin{array}{c}\text { Cerebral palsy } \\
\text { Spastic tetra -paresis } \\
\text { pred ominantly hemi- } \\
\text { paresis -left side }\end{array}$ & 4 & M \\
\hline 2. & DG & $\begin{array}{c}\text { Cerebral palsy } \\
\text { Spastic tetra- paresis }\end{array}$ & 4 & F \\
\hline 3. & A.A & $\begin{array}{c}\text { Cerebral palsy } \\
\text { Spastic tetra-paresis }\end{array}$ & 10 & F \\
\hline 4. & EU & $\begin{array}{c}\text { Cerebral palsy } \\
\text { Spastic etra -paresis } \\
\text { pred ominantly hemi- } \\
\text { paresis left side }\end{array}$ & 10 & F \\
\hline 5. & TD & $\begin{array}{c}\text { Cerebral palsy } \\
\text { Spastic tetra-paresis }\end{array}$ & 12 & M \\
\hline
\end{tabular}

A complex assessment was done to the children concerning the body attitude, the hypertonia of the upper and lower limbs, the functionality of the upper limbs and general motor functionality.

All children in the study presented a characteristic attitude of the upper limbs dysfunction in adduction, flexion and pronation, and the lower limbs in flexion, adduction, internal rotation and equin - varus; more or less visible, depending on the degree of disease.

The assessment of the spasticity of the upper and lower limbs was done through Ashworth scale by assessing resistance to passive muscle stretching[6].

In order to evaluate the functionality of the upper limbs, the Manual Ability Classification Symmetry System, MACS, was used.

The global motor functional evaluation GMFE measured the changes in overall functional motility while in supine, sitting, the dog position (four paws), kneeling, standing and walking.[7] Factors that contributed to the choice of selected therapy were: type of the motor abnormalities, the degree of the spasticity and its causes, general physical condition and the level of child development, the strength and muscle control, the balance and stability the functional abilities, age of the child.

The major objective of recovering the child with infantile cerebral palsy was to improve the quality of life by creating conditions to ensure minimum patient autonomy[4,8].

The specific objectives pursued in the recovery program are:

$\checkmark \quad$ inhibition of muscle spasticity / hypertonia;

$\checkmark \quad$ promoting controlled mobility;

$\checkmark \quad$ increasing stability in different postures;

$\checkmark \quad$ preventing musculoskeletal reactions by suppressing reflex tonic activity;

$\checkmark \quad$ facilitating controlled motor activity;

$\checkmark \quad$ developing gripping and manual ability;

$\checkmark \quad$ developing awareness of the body scheme; 


\section{$\checkmark \quad$ stimulation of the motor control; \\ $\checkmark \quad$ developing and strengthening equilibrium responses; \\ $\checkmark \quad$ learning to walk.}

The functional recovery program was running 3 times a week, applying and the Vojta method by a specialized therapist. The session was 50-60 minutes.

Methodological indications of treatment:

1. the realization of the program took into account the stages of neuro-motor development of the child;

2. exercises were performed based on the original positions with high base support (DV DD) and later gradually the base support was lowerred;

3. passive stretching by stretching the muscle for about 10 seconds allowed control of spasticity, decreasing muscle tension, which has led to physical and mental relaxation of patients; [6]

4. the exercises were carried out from simple to complex, following the principle of progressivity ;

5. the exercises have been explained and practiced with parents / guardians so that they can be practiced at home;

6. dosage, (number and frequency) and change of exercises is done by kinetotherapist depending on the child's condition and progress ;

7. and it was kept the patient's response to each exercise conditions adapted or used stimuli to motivate it and / or you relax.

The proposed kinetotherapy program included:

- Exercises to relax and reduce spasticity at the beginning of the session-approx. 10-15 minutes[8];

- Exercises for the development of gripping about. 10 minutes;

- Exercises for limbs and trunk-approx.10 minutes;

- Steady-and-go exercises. 10 minutes;

- Occupational therapy (toys) about. 10 minutes.

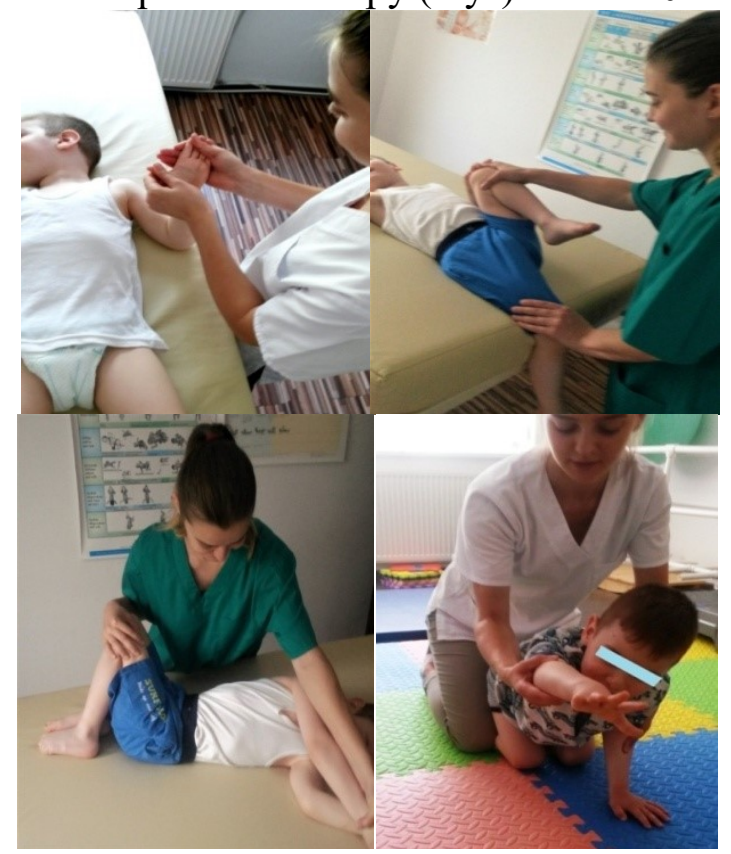



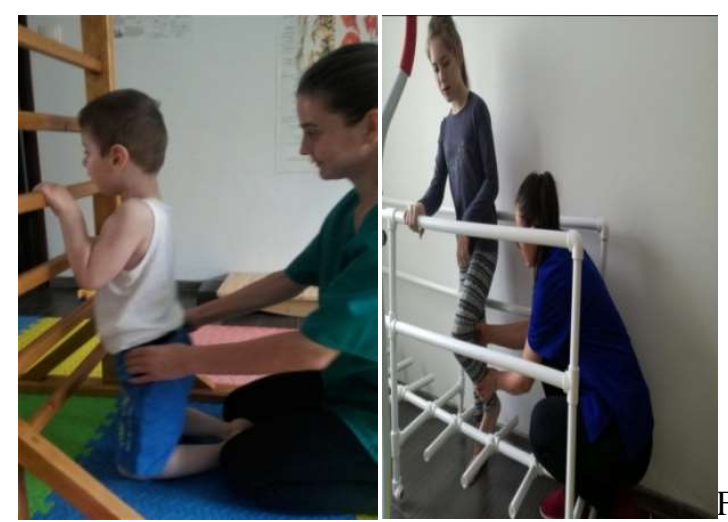

Fig. 1 Exercises in decubitus, knee and orthostatism

\section{Results and discussions}

After application of interventional kinetotherapy in children with cerebral palsy small changes in body attitude were observed due to the decrease of hypertonia in the upper limbs and lower limbs.

Following the evaluation of hypertonia through the ASWORTH scale we found the following: initial spasticity at the level of iliopsoas varies between 2-4 with an average of 3.2 ( \pm $0.447)$ right side $2.8( \pm 0.887)$ left side and finally the spasticity diminished ranging between $0-3$ with an average of $1.6( \pm 1.440)$ right side and $2( \pm 0.707)$ left side. Ischiogambiers recorded initial values between 1-4 with an average of $2( \pm 1,000)$ right side and 2,4 $( \pm 0,894)$ left side;final values between $0-3$ with an average of $1( \pm 1,000)$ right side, and 1,6 $( \pm 0,894)$ left side and triceps sural initial values between 1-4 with an average of 2,8 $( \pm 1,304)$ left side, and $3( \pm$ $1,225)$ and final values between $0-3$ with an average of $1,4( \pm 1,342)$ right side and $2,2( \pm 0,837)$ left side. At the upper limbs level hypertonia was recorded on the brachial biceps, the supinators and the flexors of the fingers and fist, so the initial biceps recorded values between 0-4 with an average of $2( \pm 1,581)$ right side and 2,6 $( \pm 0,894)$ left side, final values between 0 - 3 with an average of $1.4( \pm 1.342)$ right side and $1.8( \pm 0.837)$ left side; supinators initial and final values between $0-3$ with an initial mean of $1.6( \pm 1.140)$ right side, $2.2( \pm 0.837)$ left side, and final of 1 $( \pm 1.225) \mathrm{dr}$ and $1.2( \pm 1.095)$; flexion of fingers and fingers recorded initial values between $0-4$ with an average of $2.2( \pm 1.643)$ right side, and $2.6( \pm 1.140)$ left side, and final values between $0-3$ with an average of $1.4( \pm 1,342)$ was $1.6( \pm 1,140)$.

The highest values of hypertonia recorded the TD patient because it did not perform specific kinetic recovery for a long period of time, and there were also observed muscles and tendons retractions.

From their results from the initial and final notice an improvement in the tone of it all muscles tested, registering a decrease of resistance on all muscle groups.

To assess the functionality of the upper limbs, the Manual Ability Classification System for Children with CP was used, the Manual Ability Classification System, MACS

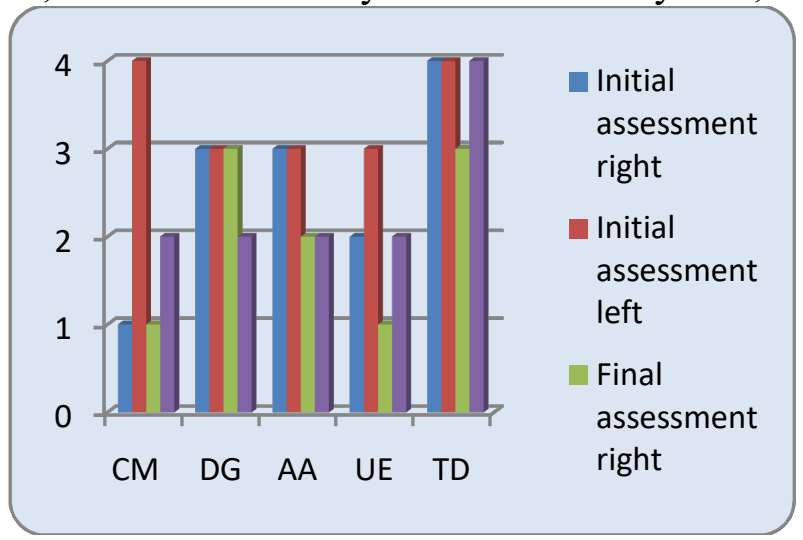

Fig.2 Evolution of superior limb functionality 
As noted in the initial assessment, almost all tested patients handle objects with difficulty, or need help to prepare activities that can be performed independently, except for the TD patient who handles a limited range of simple objects and requires permanent support and assistance or adapted equipment. Following the final evaluation, most patients fall into Grade II manipulating most objects but with quality and / or low speed, the TD patient remaining at the same level

The overall motorfunctional evaluation was performed using the EMFG or GMFM Scale.

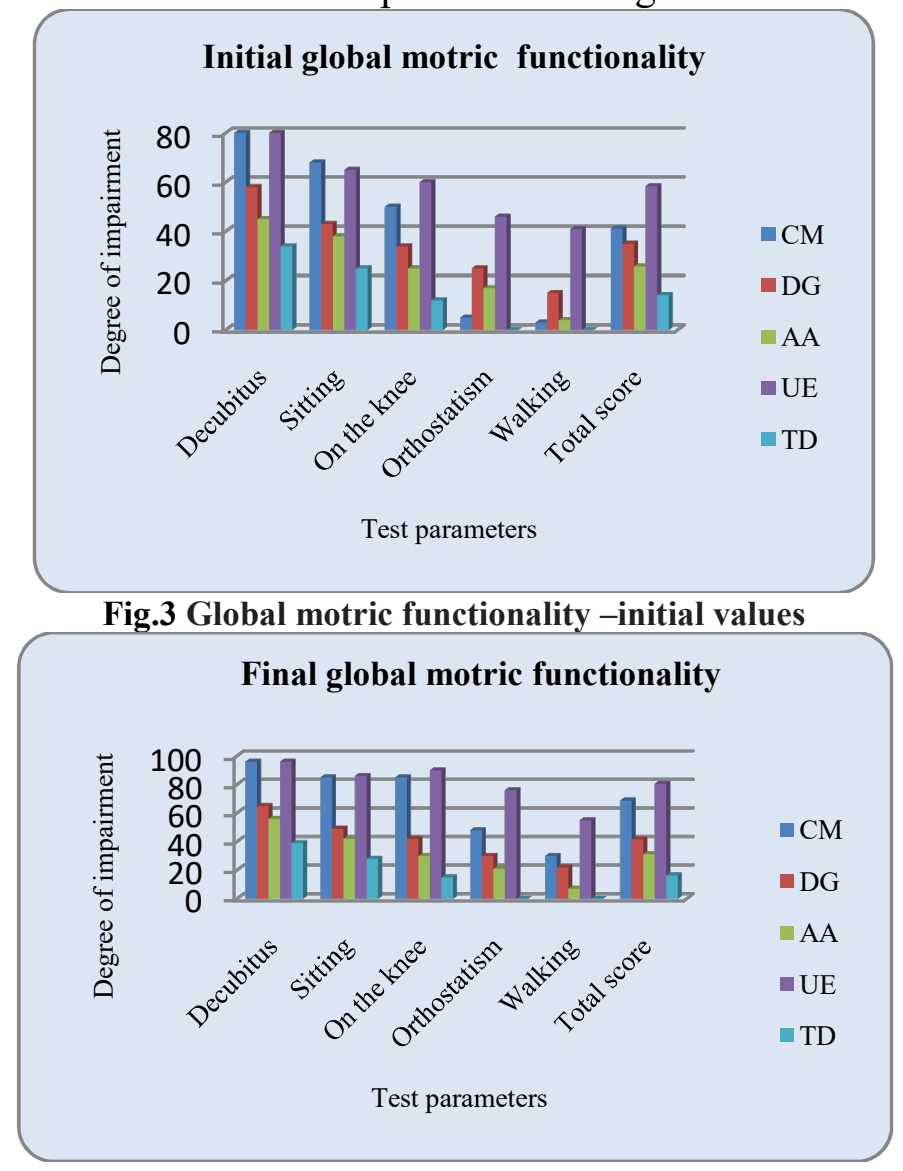

Fig.4 Global motric functionality -final values

For the study group of the $\mathrm{CP}$ and the average values initial were: A (decubitus) $59.4( \pm 20.63)$ score $B$ (sitting) of $47.8( \pm 18.32)$ score $C$ (kneeling) of $36.2( \pm 19.18)$, D score (standing) of $18.6( \pm 18.20)$, score E (walking) of $12.6( \pm 16.86)$.

The mean final score was: A (decubitus) of $70.4( \pm 25.16)$, Score B (sittingt) of $88( \pm 26.22), C$ Score (On Knees) of $52.4( \pm 33), 48)$, D score (standing) of $35( \pm 28.70)$, E (walking) score of $22.8( \pm 21.55)$.

After evaluating the percentage score on the 5 sections, the 5 subjects with spastic form of CP, the mean total initial value was $34.92( \pm 16.60)$ and the final of $47.72( \pm 26.53)$. Evaluation of the total percentage score (\%) of GMFM in spastic CP subjects

demonstrated the lowest values in the TD subject with tetraplegia, the severe form, UL (upper limbs) being as severely affected as LL (lower limbs).

\section{Conclusions}

Stretching exercises, neuro-motor reeducation methods and active physical exercises help increase functional independence by: reaching the concept of normality; awareness of body scheme and body skills; increasing self-confidence; multilateral development of personality of the children with $\mathrm{CP}$ and the recovery..

The Kabat method, Le Metayer and the Vojta methods can help maintain and increase range of motion of the joints, decrease of the spasticity, maintain and / or increase excitability of the 
muscles, maintain kinesthetic memory of movements, preventing the joints stiffness, improving postural control, coordination of movements and the balance generally [4].

The individualized physical therapy program, well done, gains and / or obtained maintenance control of the other positions by increasing the coordination and static and dynamic balance, and was confirmed as a result of centralization of data according to the rating scale motor overall functional positions lying, sitting, quadrupeds and knees, standing, walking .

Recovering the child with $\mathrm{PC}$ is a complex interdisciplinary process which is striking by multiple factors: education and information of parents or foster parents of the child with $\mathrm{CP}$, about socio-economic level and low access to community-based recovery services; of the diseases associated especially with epilepsy and severe and profound mental retardation, the increased cost of the therapy.

Every effort must be made in the recovery program, as far as possible, of the overall rehabilitation of the child, in close correlation with its family and social environment. Regarding the development of the recovery methodology, the basic problem remains the elaboration and implementation of development-oriented recovery models as well as of models that would cover all the levels of medical-social assistance.

\section{References}

1. BOBATH K “Cerebral palsy: Hope and through research", National Institute of Neurological Disorders and Stroke, July 2001;

2. ROBĂNESCU N. „Tratamentul sechelelor motorii ale encefalopatiilor infantile (Paralizia spastică cerebrală)", Editura Medicală-București 1983;

3. MOȚET D., Psihopedagogia recuperării handicapurilor neuromotorii, Ed. Fundaţiei Humanitas, Bucureşti, 2001;

4. ZOLTAN Pazstai „Kinetoterapia în afecţiuni neuropediatrice”, Universitatea din Oradea 2004;

5. *** Studiu clinic din România pentru tratarea copiilor cu paralizie cerebrală, iniţiat de Cord Blood Center, prima bancă de celule stem;

6. CĂCIULAN Elena, STANCA Daniela, „Paralizia cerebrală infantilă Infirmitatea motoriecerebrală Evaluare şi Kinetoterapie” Editura MOROŞAN, Bucureşti 2011;

7. FLETT PJ. -Rehabilitation of spasticity and related problems in childhood cerebral palsy. $\mathbf{J}$ Paediatr Child Health 2003; 39: 6-14. 127 - 96;

8. FREEMAN MILLER - Physical Therapy of Cerebral Palsy, Ed Springer, 2007. 